\title{
EL ÁRBOL EN PARADISO: LA METÁFORA Y SU DOBLE
}

\begin{abstract}
Dans le règne de l'imagination, à toute immanence s'adjoint une trascendence. C'est la loi même de l'expression poétique de dépasser la pensée...Alors s'impose le réalisme de l'irréalité. On comprend les figures par leur transfiguration. La parole est une prophétie.
\end{abstract}

GASTON BACHELARD, $L$ 'air et les songes

Una de las metáforas más insistentes en Paradiso ${ }^{1}$ es la del árbol. En proliferación verdaderamente "arborescente" y de múltiples connotaciones, aparecen ciervos con la "cornamenta arbórea llena de pájaros", familias que "al entroncarse se perdían en ramificaciones infinitas, en dispersiones y reencuentros", eucaliptos con "troncones como elefantes", falos arborescentes, fruteros transfigurados en "árboles marinos", mieles cuyo "calor limpia el árbol bronquial de cargazones y ramajes cansados"... Por otra parte, a varios personajes se les asocia consistentemente con un árbol: José Eugenio Cemí tiene "la base como una raíz. Cuando [está] parado parece que [está] creciendo, pero hacia adentro, hacia el sueño" (p. 96) ${ }^{2}$; Alberto, "cuando [penetra] en cualquier ámbito lo [modifica] desde su raíz"' (p. 185); Fronesis es el árbol "regado por los incesantes y enloquecidos paseos cir-

1 Todas las referencias a Paradiso incluidas entre paréntesis en el texto son de la edición de Era, México, 1976.

${ }^{2}$ Son muchas las resonancias de esta imagen. Por una parte, José Eugenio Cemí "crece hacia adentro, hacia el sueño", el sueño de la muerte prematura; pero, por otra parte, uno de los símbolos favoritos de Lezama, el de la noche de los Idumeos, que en el sueño crean el árbol, reactiva el sentido de esta metáfora, sugiriendo así la naturaleza creadora del árbol de sueño que 
culares" de Fociórı (p. 393); Cemí, constantemente agobiado por "el repliegue del árbol bronquial"' (p. 258), se transfigura en un Árbol cósmico justo antes de su encuentro póstumo con Oppiano Licario en la "casa lucífuga", como preludio al despertar poético que es el fin de la novela (en el principio está el fin).

No obstante la extraordinaria riqueza y complejidad de esta imagen en el plano verbal, el proceso metafórico se extiende a otros planos. En el plano diegético, o del universo de la ficción, el árbol aparece varias veces como elemento que forma parte del relato: Foción enloquecido dando vueltas a un árbol, por ejemplo, o el episodio de los presos cortando un árbol en el campamento; ambos episodios ocurren antes de una muerte, la de doña Augusta en el primero, la del Coronel Cemí en el segundo. La yuxtaposición, sin embargo, ni obedece necesariamente a una causalidad de orden cronológico, ni está subordinada lógicamente al episodio central en cuestión, la muerte. Es una causalidad metafórica la que en ambos casos determina la yuxtaposición y nos obliga a una lectura simbólica de estos "montajes": actos premonitorios en los que se manifiestan, como en tantas otras ocasiones, "las potencias de la destrucción".

De este modo, el proceso metafórico se activa también en el plano del discurso narrativo. En relación a la metáfora del árbol, podemos observar que, a lo largo de la novela, la distribución de unidades narrativas responde consistentemente a un doble movimiento de unificación y dispersión, que a su vez se asocian, a nivel verbal, con la raíz, el tronco y las ramas de un árbol ${ }^{3}$. En los capítulos I y II, por ejemplo, el campamento está descrito alrededor de un centro, físico y moral; el Coronel Cemí. Aparecen luego, en yuxtaposiciones hasta entonces inmotivadas, una serie de personajes - Adalberto Kuller, Martincillo, Vivo, etc. - cuya función no es clara y cuya presencia intermitente, igualmente inmotivada, los hace aún más enigmáticos. No es sino hacia el final del libro, en el alucinante movimiento de unificación, cuando cobran sentido estos personajes, al convergir en ese centro-ausencia fundamental que es Oppiano Licario.

es el Coronel Cemí, "en la marcha de lo irreal hacia lo real, dormir es estar entrañablemente despierto", "Introducción a un sistema poético", en Obras completas, Aguilar, México, 1977, t. 2, p. 396.

3 (José Eugenio) "Los Méndez en una apetencia que desconocía más su finalidad, tal vez por ser más soterrada, buscaban en mi padre su encarnación, su tierra, su cuerpo árbol. A su muerte, la dispersión"' (p. 127). 
Adalberto Kuller se preocupaba en la poesía más de la voluptuosidad que del aliento, de la evaporación vital que las palabras lograban atesorar [...] aquella puerta idiota [la del ómnibus] que lo recogía como si fuera una rama desgobernada, suelta, de un arraigamiento invisible (p. 433).

Adalberto Kuller, Martincillo, Vivo... dispersión por los sentidos $^{4}$. Si al principio de la novela opera sobre estas ramas secundarias una fuerza centrífuga, ahora, ante la presencia de Licario (ausencia-extensión relacionable-centro de imantación), una fuerza centrípeta los imanta, reuniéndolos en un agrupamiento arborescente.

En el ejemplo anterior, la distancia entre el movimiento diversificador y el unificador es tan grande que abarca casi toda la novela; en la disposición de otras unidades narrativas, la distancia puede ser menor. Podemos señalar como ejemplo la cena presidida por doña Augusta y la muerte de Alberto, en el capítulo VII. La detallada descripción de la cena, especialmente la improvisada "naturaleza muerta" que hace Alberto sobre la mesa, no es un simple ornamento descriptivo; responde, una vez más, a una causalidad de orden metafórico.

El frutero se había colocado al centro de la mesa, sobre una de las manchas de remolacha. Alberto cogió uno de los langostinos, lo verticalizó como si fuese a subir por el pie del cristal, hasta hundir sus pinzas en la fruta más rendida. El frutero, como un árbol marino al recibir el rasponazo de un pez, chisporroteó en una cascada de colores, estirándose el langostino contento de la nueva temperatura como si quisiera llegar al cielo curvo del plato pintado de frutas (p. 198).

Todo aquí converge hacia un centro: la descripción en sí es central en el episodio, la presencia de doña Augusta como centro irradiante, el "árbol marino" en el centro de la mesa, y todo en un afán de elevación que recibe su respuesta en la "cascada de colores" que desciende sobre el langostino que asciende. Alberto está siempre asociado con el cangrejo, y comparte con él su doble simbolismo; por una parte, el cangrejo como regresión, involución hacia el caos, por otra como regeneración (como el escarabajo egipcio, el cangrejo devora lo que es transitorio, contribuyendo así a una incesante regeneración física y moral) ${ }^{5}$. Aquí, en presen-

4 "Cuando el potens actúa en lo visible, sus derivaciones son el dominio de la physis...", "Preludio a las eras imaginarias", en Obras completas, t. 2, p. 819. ${ }^{5}$ Véase crab en A. DE VRIES, Dictionary of Symbols and Imagery, North Holland, Amsterdam-London, 1974. 
cia de un centro, el langostino se impulsa en un movimiento ascensional. Pero ante la noticia de la enfermedad mortal de su madre, sobreviene la disolución para Alberto:

doña Augusta había destellado en el centro de su familia como una gema en el centro de sus irradiaciones. Una comida familiar que había mezclado la gravedad y la sencillez, les avisaba que había llegado la dispersión (p. 200).

La imagen poética que corresponde a la disolución, al final del capítulo, es la del langostino que avanza "al refractarse los colores frutales, hacia un cementerio de coral" (p. 211). Sólo Licario, ese centro ausente de toda la novela, podía haber evitado el descentramiento y la dispersión para Alberto. Pero "el mediador, el que le sale al paso a la ananké, abandonaba el campo a las potencias de la destrucción" (p. 201).

"Las potencias de la destrucción"' hacen su entrada, inmediatamente después, en la persona del guitarrista mexicano, completando así el movimiento centrífugo hacia la dispersión. El charro es también un ente de luz, pero no la luz que desciende como respuesta a la progresión ascendente que parte de un centro, sino "tachones de plata", "exceso de luces" que "daban al guitarrista mexicano un resplandor infernal" (p. 201). El charro es un "trompo infernal", "latigazos del rabo del chivo negro que acompaña al diablo".

En una lectura retrospectiva, que sólo una lectura metafórica hace posible ${ }^{6}$, resuenan los agrupamientos espaciales de Cemí en la composición marino-arbórea de Alberto:

Casi siempre la adquisición del objeto se debía a que ya frente a la vitrina, cuando comenzaban a distinguirse algunos pespuntes coloreados, en el momento en que su mirada lo distinguía y lo aislaba del resto de los objetos, lo adelantaba como una pieza de aje-

6 “'La métaphore est un pur dynamisme, et pas seulement un dynamisme à sens unique... mais un dynamisme double, symmétrique, qui permet aussi bien de renverser l'ordre de succession du procès métaphorique... et fait ainsi du trope le lieu d'une tension où le sens est soumis à un perpetuel va-et-vient $[\ldots]$ si le fonctionnement interne de la métaphore (c'est-à-dire la métaphore isolée en tant qu'unité paradigmatique) se définit par un va-et-vient constant du sens (la reversibilité), on peut dire que son fonctionnement externe (c'est-à-dire la métaphore en position syntagmatique) transfère ce dynamisme sémantique interne à l'ensemble du texte [...] un trope n'est quasi jamais ponctuel, $[\ldots]$ il dépasse l'unité du simple syntagme pour s'étendre a l'echelle de la phrase et même surtout, du texte", PHILIPPE DUBOIS, "La métaphore filée et le fonctionnement du texte'", FrM, 43 (1975), 202-213. 
drez que penetra en un mundo que logra en un instante recomponer todos sus cristales. Sabía que esa pieza que se adelantaba era un punto que lograba una infinita corriente de analogía (p. 377).

Entonces comprendió que la desazón caótica que mostraba la vitrina de la calle de Obispo, se remansaba en la caoba pulimentada que cerraba por arriba el estante, al situarse la copa entre las dos estatuillas de bronce. Parecía que el ángel corría y saltaba sin marearse por el círculo de los bordes de la copa, y que la bacante, fatigada del golpear de sus címbalos y de sus aparatosos saltos, se hundía hasta el pie de la copa, donde el ángel intentaba recuperarla para los juegos de la luz redonda por los bordes de la copa (p. 379).

Esa "infinita corriente de analogía" circula entre la bacante que se hunde hasta el pie de la copa y el ángel que intenta recuperarla, por una parte, y por otra, el langostino que sube por el pie del cristal y la respuesta de la fruta en la cascada de colores; entre la copa, el frutero, y la copa con sangre, cálices del Santo Grial, en la casa al final del bosque, en la visión de unidad de Cemí.

A su vez, el episodio de la muerte de Alberto establece nexos de orden metafórico con el episodio de la "casa lucífuga" en el último capítulo: dos "isotopías" de signo inverso - Alberto y Cemí- unidas por "semas" narrativos idénticos: los eucaliptos "con troncones como elefantes"' (pp. 208 y 484), el cangrejo y la caries dental, los versos "Ceñido el amanecer..." (pp. 209 y 483) y "Un collar tiene el cochino..." (pp. 210 y 487); el guitarrista y el viejo del "whip" (cf. los "latigazos del rabo..."), ambos asociados con el diablo, ambos con manchas negras en la cara ("carbones en la frente" el guitarrista, espinilla negra el viejo), ambos asociados con luz centrífuga y fragmentaria ("trompo infernal", "tachones de plata" el guitarrista; "timonel de una máquina infernal", "una estrella giratoria y un whip", música que se refracta y desprende "como centellitas", el viejo, p. 484).

Estas dos realidades de signo opuesto y a la vez complementarias desembocan en una tercera: la visión de unidad que incorpora y trasciende los dos planos analogados. Porque, a diferencia de Alberto, Cemí, al atravesar el mismo bosque "donde los árboles trepaban unos sobre otros" como elefantes, llega a la casa, "bosque en la sobrenaturaleza", que es la visión de unidad:

cada trébol representaba una llave, como si se unieran la naturaleza y la sobrenaturaleza en algo hecho para penetrar, para saltar de una región a otra, para llegar al castillo, e interrumpir la fiesta de los trovadores herméticos. Una guirnalda entrelazaba el Eros y el Tánatos, el sumergimiento en la vulva era la resurrección en el valle del esplendor (p. 485). 
Si Alberto era "el idioma hecho naturaleza"' (p. 183), Cemí, a partir de la res extensa que es Licario, será el idioma hecho sobrenaturaleza. "La energía en la extensión tiene que crear el árbol"?. No es entonces casual que sea precisamente en este último capítulo donde vemos a Cemí transfigurado en un Árbol Cósmico.

Sentía dos noches. Una, la que sus ojos miraban avanzando a su lado. Otra, la que trazaba cordeles y laberintos entre sus piernas. La primera noche seguía los dictados lunares, sus ojos eran también astros errantes. La otra noche se teñía con el humillo de la tierra, sus piernas gravitaban hacia las entrañas terrenales. Bajaba los párpados, le parecía ver sus ojos errantes describiendo órbitas elípticas en torno al humillo evaporado o el animal carbunclo.

Una era la noche estelar que descendía con el rocío. La otra era la noche subterránea que ascendía como un árbol, que sostenía el misterio de la entrada en la ciudad (p. 481).

En este rito iniciático que es Paradiso, el viaje de la naturaleza a la sobrenaturaleza se efectúa a través de la poesía. Para el aspirante a poeta, sin embargo, las pruebas y combates para reducir el caos a sustancia poética no se hacen afuera sino en su interior. Cemí, a diferencia del San Jorge de la resurrección, "No libró ningún combate, pues jadear / fue la costumbre establecida entre su hálito / y la brisa o la tempestad..." (p. 359). Esa lucha contra los "repliegues" y contracciones de su "árbol bronquial" marca las etapas en este proceso de transfiguración. Al principio el asma lo agobia al grado de tener miedo de quedarse dormido; más tarde es por un artificio - los polvos fumigatorios- como logra el equilibrio, el sueño ya no es temido sino buscado; el efecto es "dilatar el ramaje de su árbol bronquial, hasta lograr la equivalencia armónica entre el espacio interior y el espacio externo" (p. 246). En esa armonía hay un sentimiento de reconciliación y un silencio que se describe como el "silencio de la araña en su ámbito, silencio del ángel en su transparencia universal"' (p. 248). Ahora bien, en el sistema poético de Lezama, es por el aliento que "el cuerpo toca en un punto con lo invisible"' y "el primer encuentro de la poesía es ese punto órfico, esa respiración que se mueve entre el cuerpo y un espacio como el de la araña al formar ámbito y hechizo. Esa respiración es el primer apresamiento de lo sobreabundante, de la liberación concupiscible...En realidad,

7 “La dignidad de la poesía", en Obras completas, t. 2. pp. 788-789.

8 Ibid., p. 775. 
la primera aparición de la poesía es una dimensión, un extenso, una cantidad secreta, no percibida por los sentidos"'9. La relación que se establece entre aliento y extensión es tan estrecha y dinámica que es imposible distinguir entre los dos. La respiración anima con su movimiento y da contorno a la extensión.

El signo, pasado a la expresión hace que la letra siempre tenga espíritu. En el signo hay siempre como la impulsión que lo agita y el desciframiento consecuente. En el signo hay siempre un pneuma que lo impulsa y un desciframiento, en la sentencia, que lo resume $^{10}$.

Así, la expansión bronquial en Cemí, y la armonía entre espacio interior y exterior que de ella resulta, son correlatos metafóricos de esa "extensión" y "La energía en la extensión tiene que crear el árbol"'; "en ese simbolismo corporal", dice Lezama en "Introducción a un sistema poético" "las distancias del cuerpo corresponden a sus posibilidades de creación" "11. Cemí, en ese equilibrio logrado, está ya listo para ese proceso de mitificación. Ya en el capítulo $\mathrm{X}$ esta proyección al plano cósmico empieza a llevarse a cabo.

Una estrella verde, fría como la menta, pasó por encima del árbol bronquial de Cemí. Sintió que su trompetica de plata, sus alveolos bronquiales comenzaban a tañer (p. 306).

Cemí, en tanto que Árbol Cósmico, comparte todos los atributos del símbolo. El simbolismo del árbol reúne todas las imágenes de la totalización cósmica. Cemí-árbol se asemeja al Yaggdrasil de los nórdicos, cuyas raíces se hunden en el centro de la tierra y sus ramas tocan el firmamento" . "Hay ejemplos", dice Mircea Eliade "en los que el Árbol Cósmico se revela principalmente como imago mundi y en otros se presenta como axis mundi, como un polo que sostiene el firmamento y une las tres regiones cósmicas (el Cielo, la Tierra y el Infierno), y al mismo tiempo, hace posible la comunicación entre el Cielo y la Tierra. En otras variantes se enfatiza la función de la regeneración periódica del

\footnotetext{
${ }^{9}$ Ibid., p. 762.

10 "Preludio a las eras imaginarias", p. 811.

11 "Introducción a un sistema poético", p. 399.

${ }^{12} \mathrm{G}$. DURAND, Les structures anthropologiques de l'imaginaire. Introduction à la archétypologie générale, Imprimérie Allier, Grenoble, 1960.
} 
universo o el papel del Árbol Cósmico como Centro del Mundo, o su potencialidad creadora" 13 .

Todos estos atributos del Árbol Cósmico están presentes en la imagen del árbol en Paradiso. Más aún, esta imagen con todas sus connotaciones corresponde, casi punto por punto, al concepto de metáfora que Lezama ha elaborado en sus ensayos, concepto frecuentemente definido, a su vez, metafóricamente, como el proceso de creación de un árbol.

Yo diría que la sustitución o metáfora es posible en la identidad, porque la identidad es posible en su prolongación, que es la extensión ${ }^{14}$.

La identidad que es la extensión crea el ser, como la extensión crea el árbol ${ }^{15}$.

La extensión es una "unidad de sustancia idéntica", pero esta identidad no es estática sino dinámica; es un "continuo sucesivo" en el que actúa la energía creadora (¿neuma universal, tal vez? $\left.{ }^{16}\right)$. "La energía", dice Lezama en "Plenitud relacionable", "si actúa sobre un punto lo destruye; si sobre un plano, tiende a convertirse en un estado de duración" ${ }^{17}$. La "extensión" es pues, para Lezama, una dimensión espacio-temporal dinamizada, que hace posible la creación (y el espacio corporal se convierte así en la metáfora que corresponde a la "extensión irradiante" que a su vez hace posible la metáfora).

...sólo el hombre al ascender del germen, lo hace por medio de un acto, que reobra constantemente sobre el germen, procurando por ese acto volcar de nuevo su germen en una nueva extensión. Ese reobrar del acto sobre el germen engendra un ser causal nutrido con

13 Mircea Eliade, Myths, Rites, Symbols, Harper, New York, 1975, t. 2, p. 38 (la traducción es mía).

14 "Preludio a las eras imaginarias", p. 805.

15 Ibid., p. 797.

16 (Fronesis) "Desde que el neuma universal [...] soportó un espacio interior ejercitado en los cuerpos, en realidad el laberinto corporal es la única forma de aprehensión de ese espacio ocupado totalmente por ese neuma o hálito universal, pues el hombre apareció como una transición misteriosa entre el espíritu de un espacio errante y el hálito hipostasiado en un laberinto que era su cuerpo"' (Paradiso, p. 277).

17 "Plenitud relacionable", en Obras completas, t. 2. p. 476. 
los inmensos recursos de la vivencia oblicua y un súbito, que hace la extensión creadora, dándole un árbol a esa extensión, haciendo del árbol el uno, el esse sustancialis, y aquí comienza la nueva fiesta de la poesía, el potens, el posible en la infinitud. Es decir, el hombre puede prolongar su acto hasta llevar su ser causal a la infinitud, por medio de un doble que es la poesía ${ }^{18}$.

En el texto anterior se perfila el proceso metafórico como una progresión de virtual a virtual, es decir, de extensión a extensión: el doble movimiento ascensional/descensional generado por un espacio creador, en cuyo espacio interseccional se dan la "vivencia oblicua" y "el súbito" que generan a su vez una nueva extensión creadora de la cual surgirá, una vez más, el árbol, el esse sustancialis. Se inicia un nuevo ciclo: como la regeneración periódica del Árbol Cósmico a partir de la identidad y prolongación de su ser.

En los términos de mi sistema poético del mundo, la metáfora y la imagen tienen tanto de carnalidad, pulpa dentro del propio poema como de eficacia filosófica, mundo exterior o razón en sí. Es uno de los misterios de la poesía la relación que hay entre el análogo, o fuerza conectiva de la metáfora, que avanza creando lo que pudiéramos llamar el territorio substantivo de la poesía con el final de este avance, a través de infinitas analogías, hasta donde se encuentra la imagen, que tiene poderosa fuerza regresiva, capaz de cubrir esa sustantividad. La relación entre la metáfora y la imagen se puede establecer con un caballo tan alado como nadante que persiste en una sustancia resistente que en definitiva podemos considerar como la imagen. La imagen es la realidad del mundo invisible...Yo creo que la maravilla de un poema es que llega a crear un cuerpo, una sustancia resistente enclavada entre una metáfora que avanza creando infinitas conexiones, y una imagen final que asegura la pervivencia de esa sustancia, esa poiesis ${ }^{19}$.

Este movimiento ascendente y progresivo de la metáfora, contrapunteado por el movimiento descendente y regresivo de la imagen, la nueva visión que surge de la unión de lo dinámico y lo inmóvil, progresión metafórica/fijación de la imagen ${ }^{20}$ y la metáfora como "signo unitivo [que] puede aclarar uno de sus extre-

18 "Preludio a las eras imaginarias", p. 817.

19 Órbita de Lezama Lima, Est. prelim., sel. y notas de Armando Álvarez Bravo, Órbita, La Habana, 1966, p. 31.

20 “...esa suma de sentencias poéticas, cada una de las cuales sigue la impulsión continua de su primer remolino, recobra su sentido tonal cuando la imagen desciende sobre ellos y forma un contrapunto intersticial entre los enlaces y las pausas". ("Introducción a un sistema poético", p. 406). 
mos, mientras el otro se sumerge como un pez en la refracción anteriormente desconocida" ${ }_{21}$; oposición de lo real y lo irreal, lo visible y lo invisible, son todos ellos atributos que se observan en la constelación de imágenes que forma el simbolismo del Árbol Cósmico: movimiento ascensional a las regiones aéreas, descensional, a la raíz, al centro de la tierra, con su correspondiente oposición claridad/oscuridad; lo visible del árbol, lo invisible de sus raíces; inmovilidad del tronco, dinamismo aéreo de las hojas; permanencia y cambio incesante, etc.

Así pues, el árbol, tanto en los ensayos como en Paradiso, es un nudo de significaciones poéticas en las que Lezama se apoya para definir su concepto de metáfora, que es la esencia de la poesía. Mas no es éste un árbol de naturaleza sino de sobrenaturaleza, un Árbol Cósmico, "que sostiene el misterio de la entrada en la ciudad", que hace posible la comunicación entre la tierra y el cielo, entre la inmanencia y la trascendencia, entre la fugacidad y la permanencia. El árbol lezamiano no es sólo axis mundi e imago mundi sino imago resurrectionis.

En la resurrección se vuelca el potens, agotando sus posibilidades. Cuando el potens actúa en lo visible, sus derivaciones son en el dominio de la physis; cuando se desarrolla en lo invisible nos regala el prodigio de la imagen de la resurrección...los recursos del potens frente a la resurrección, sólo pueden ser manejados por ese ser causal, el hombre en el centro irradiante de su plenitud...sólo el poeta, dueño del acto operando en el germen, que no obstante, sigue siendo creación, llega a ser causal, a reducir, por la metáfora, a materia comparativa la totalidad ${ }^{22}$.

Como vimos antes, Lezama identifica el árbol con "el uno", "el esse sustancialis", el "potens", mismos atributos que caracterizan a la metáfora. Si tanto por la textura verbal como por la distribución de las unidades narrativas, la novela tiene una estructura arborescente; si el árbol es un correlato de la metáfora, Paradiso se nos revela como la metáfora de la metáfora, y, si la imagen, como producto final del proceso metafórico, "nos regala el prodigio de la imagen de la resurrección", todo Paradiso es la imagen de la resurrección, ese "paradiso": final que está en el principio.

21 "La dignidad de la poesía", p. 769.

22 "Preludio a las eras imaginarias", p. 819. 
Cualquier fin es el pavo, tocado por la cabeza, pero ya de nuevo empieza

a madurar por el rabo (pp. 209 y 483).

"Ritmo hesicástico, podemos empezar"'.

LUz AUrora Pimentel ANDUiza

Universidad Nacional Autónoma de México 